\title{
COMPARISON OF CONTACT STRESS OF A SPUR GEAR FOR DIFFERENT MATERIALS AND MODULES USING AGMA STANDARDS IN FEA
}

\author{
Prabhakaran $\mathbf{S}^{1}$ and Ramachandran $\mathbf{S}^{2}$ \\ ${ }^{1}$ Research Scholar, Sathyabama University, Chennai, India \\ ${ }^{2}$ Department of Mechanical Engineering, Sathyabama University, Chennai, India \\ Email: ${ }^{1}$ prabhakaran.sk1980@gmail.com
}

\section{Abstract}

Gearing is one of the most critical components in mechanical power transmission systems. This paper explains about the comparison of the geometry of spur gears for different materials and modules by modeling and mathematical equations, load distribution at various positions of the contact line and the contact stress analysis of spur gears using three-dimensional finite element method. The contact stresses were examined using three-dimensional finite element model. These stresses of different modules for different materials obtained from the finite element analysis were compared with the theoretical values. Both results agree very well. This indicates that the finite element method model is accurate.

Key words: Gearing, transmission system, bending stresses, Root stresses, finite element method.

\section{INTRODUCTION}

Gearing is one of the most critical components in a mechanical power transmission system, and in most industrial rotating machinery. It is possible that gears will predominate as the most effective means of transmitting power in future machines due to their high degree of reliability and compactness [1]. In addition, the rapid shift in the industry from heavy industries such as shipbuilding to industries such as automobile manufacture and office automation tools will necessitate a refined application of gear technology [2].

A gearbox as usually used in the transmission system is also called a speed reducer, gear head, gear reducer etc., which consists of a set of gears, shafts and bearings that are factory mounted in an enclosed lubricated housing. Speed reducers are available in a broad range of sizes, capacities and speed ratios [3]. Their job is to convert the input provided by a prime mover (usually an electric motor) into an output with lower speed and correspondingly higher torque. The increasing demand for quiet power transmission in machines, vehicles, elevators and generators, has created a growing demand for a more precise analysis of the characteristics of gear systems. In the automobile industry, the largest manufacturer of gears, higher reliability and lighter weight gears are necessary as lighter automobiles continue to be in demand. Pitting is a surface fatigue failure resulting from repetitions of high contact stress [4]. The surface fatigue mechanism is not definitively understood. The contact- affected zone, in the absence of surface shearing tractions, entertains compressive principal stresses. Rotary fatigue has its cracks grown at or near the surfaces in the presence of tensile stresses, which are associated with crack propagation, ends to catastrophic failure [5].

Fig. 1. shows the Nomenclature of gear

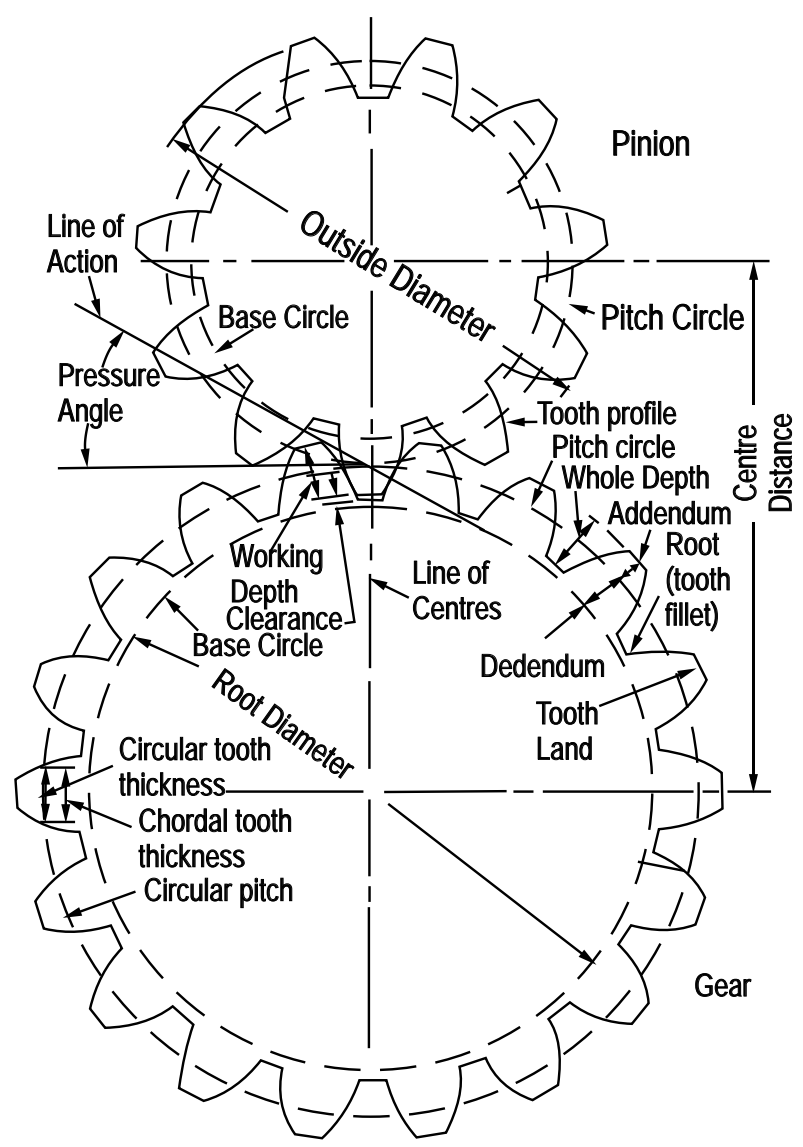

Fig. 1. Nomenclature of gear 
The finite element method is proficient to supply this information but the time required to generate proper model is a large [6]. Therefore to reduce the modeling time a pre-processor method that builds up the geometry required for finite element analysis may be used, such as Pro/Engineer. Pro/Engineer can generate three dimensional models of gears. In Pro/Engineer the generated model geometry is opened in ANSYS for analysis [7]. The major cause of vibration and noise in a gear system is the transmission error between the meshing gears. By definition transmission error is the difference between the theoretical and the actual position between driving gear and the driven gear. It can be defined also as the amount by which the ratio at a given point in a revolution departs from the correct ratio.

\section{SPUR GEAR DESIGN}

The gear design problem are taken as, a pair of spur gears with pinion 17 teeth to transmit $25 \mathrm{~kW}$ at $1500 \mathrm{rpm}$. The gear has 44 teeth at $635 \mathrm{rpm}$ and the material for gear pair is steel C45 as shown in Fig. 2. The pressure angle is $20^{\circ}$ and module $6 \mathrm{~mm}$. The above problem the objective functions as follows:

Design Objectives. The design objectives considered in the gear design are, Minimization of the overall weight, Minimization of the centre distance, life expectancy. The objective functions are obtained in terms of design variables Normal module $\left(m_{n}\right)$, material selection and Thickness of the gear (b) with the input parameters tabulated in Table 1.

Table 1 Required Input data for spur Gear design (Steel C45 material)

\begin{tabular}{|l|c|c|}
\hline \multicolumn{1}{|c|}{ Description } & Gear & Pinion \\
\hline Material & Steel C45 & Steel C45 \\
\hline Number of teeth(Z) & 44 & 17 \\
\hline Young's Modulus(E) & $\begin{array}{c}2.10^{\star} 105 \\
\mathrm{~N} / \mathrm{mm}^{2}\end{array}$ & $\begin{array}{c}2.10^{\star} 105 \\
\mathrm{~N} / \mathrm{mm}^{2}\end{array}$ \\
\hline Speed (N) & $635 \mathrm{rpm}$ & $1500 \mathrm{rpm}$ \\
\hline Power (P) & 25 & 25 \\
\hline Poisson Ratio & 0.3 & 0.3 \\
\hline Normal Module (M) & $6 \mathrm{~mm}$ & $6 \mathrm{~mm}$ \\
\hline Normal Pressure Angle & $20^{\circ}$ & $20^{\circ}$ \\
\hline
\end{tabular}

The gear design problem are taken as, a pair of spur gears with pinion 17 teeth to transmit $25 \mathrm{~kW}$ at $1500 \mathrm{rpm}$. The gear has 44 teeth at 635rpm and the material for gear pair is Steel $40 \mathrm{Ni} 2 \mathrm{Cr} 1 \mathrm{Mo} 28$ as shown in Fig.3. The pressure angle is $20^{\circ}$ and module $5 \mathrm{~mm}$. the input parameters tabulated in Table 2.

Table 2 Required Input data for spur Gear design (Steel 40Ni 2Cr1Mo28 material)

\begin{tabular}{|l|c|c|}
\hline \multicolumn{1}{|c|}{ Description } & Gear & Pinion \\
\hline Material & $\begin{array}{c}\text { Steel 40Ni } \\
2 \text { Cr1Mo28 }\end{array}$ & $\begin{array}{c}\text { Steel 40Ni } \\
\text { 2Cr1Mo28 }\end{array}$ \\
\hline Number of teeth(Z) & 44 & 17 \\
\hline Young's Modulus(E) & $\begin{array}{c}2.15^{\star} 105 \\
\mathrm{~N} / \mathrm{mm}^{2}\end{array}$ & $\begin{array}{c}2.15^{\star} 105 \\
\mathrm{~N} / \mathrm{mm}^{2}\end{array}$ \\
\hline Speed (N) & $635 \mathrm{rpm}$ & $1500 \mathrm{rpm}$ \\
\hline Power (P) & 25 & 25 \\
\hline Poisson Ratio & 0.3 & 0.3 \\
\hline Normal Module (M) & $5 \mathrm{~mm}$ & $5 \mathrm{~mm}$ \\
\hline Normal Pressure Angle & $20^{\circ}$ & $20^{\circ}$ \\
\hline
\end{tabular}

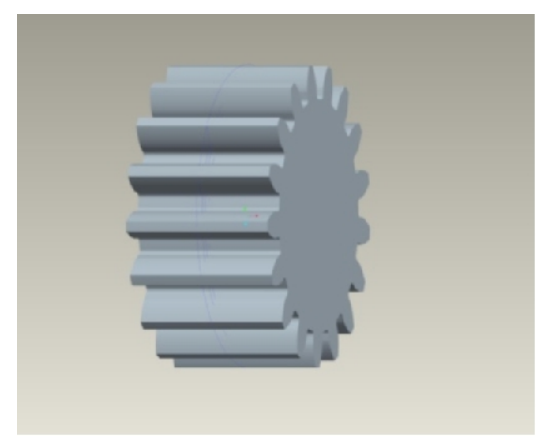

Fig. 2. Spur gear model for Steel C45

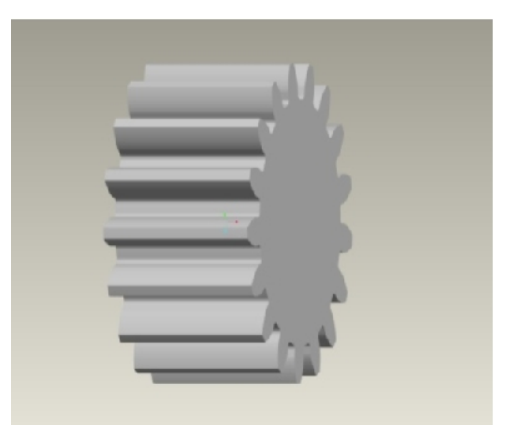

Fig. 3. Spur gear model for Steel $40 \mathrm{Ni} 2 \mathrm{Cr} 1 \mathrm{Mo} 28$ 
Table 3 Results obtained as per AGMA Standard for spur Gear design

\begin{tabular}{|c|c|c|c|}
\hline Description & Formula Used & Steel C45 & $\begin{array}{l}\text { Steel } 40 \mathrm{Ni} \\
2 \mathrm{Cr} 1 \mathrm{Mo28}\end{array}$ \\
\hline Pitch Diameter (D) & $\mathrm{m}^{*} \mathrm{z} 1$ & $102 \mathrm{~mm}$ & $85 \mathrm{~mm}$ \\
\hline Circular Pitch $(\mathrm{Pc})$ & $\pi d 1 / Z_{1}$ & $18.84 \mathrm{~mm}$ & $15.70 \mathrm{~mm}$ \\
\hline Diameter Pitch (Pd) & $\mathrm{Z1/d} 1$ & 0.16666 & 0.16666 \\
\hline Gear Ratio (i) & $\mathrm{Z2/Z1}$ & 2.58 & 2.58 \\
\hline Centre Distance (a) & $\frac{m(Z 1+Z 2)}{2}$ & $183 \mathrm{~mm}$ & $152.5 \mathrm{~mm}$ \\
\hline Pitch Line Velocity (v1) & $\frac{\pi d 1 N I}{60}$ & $8.011 \mathrm{~m} / \mathrm{sec}$ & $6.675 \mathrm{~m} / \mathrm{sec}$ \\
\hline Force exerted $(\mathrm{Ft})$ & $\underline{p}_{v} * k 0$ & $3120.67 \mathrm{~N}$ & $3745.31 \mathrm{~N}$ \\
\hline Transverse Force (Fr) & $F t * \tan \varnothing$ & $1135.83 \mathrm{~N}$ & $1363.18 \mathrm{~N}$ \\
\hline Addendum & $1 \mathrm{~m}$ & $6 \mathrm{~mm}$ & $5 \mathrm{~mm}$ \\
\hline Dedendum & $1.25 \mathrm{~m}$ & $7.5 \mathrm{~mm}$ & $6.25 \mathrm{~mm}$ \\
\hline Minimum total depth & $2.25 \mathrm{~m}$ & $13.5 \mathrm{~mm}$ & $11.25 \mathrm{~mm}$ \\
\hline Bottom Clearance & $0.25 \mathrm{~m}$ & $1.5 \mathrm{~mm}$ & $1.25 \mathrm{~mm}$ \\
\hline Fillet Radius at Root & $0.4 \mathrm{~m}$ & $2.4 \mathrm{~mm}$ & $2 \mathrm{~mm}$ \\
\hline Module (m) & $2 C /(Z 1+Z 2)$ & $6 \mathrm{~mm}$ & $5 \mathrm{~mm}$ \\
\hline Tip Diameter (da) & $(Z 1-2 f o) m$ & $114 \mathrm{~mm}$ & $95 \mathrm{~mm}$ \\
\hline Root Diameter (df) & $(Z 1-2 f o) m-2 c$ & $87 \mathrm{~mm}$ & $72 \mathrm{~mm}$ \\
\hline Initial Dynamic Load (Fd) & $\mathrm{Ft} / \mathrm{Cv}$ & $14023 N$ & $7917.54 \mathrm{~N}$ \\
\hline Velocity factor $\mathrm{Cv}$ & $6 /(+v)$ & 0.4058 & 0.473 \\
\hline Beam Strength (Fs) & $\pi * m * b *\left[\sigma_{b}\right] * y$ & $22.233^{*} 103 \mathrm{~N}$ & $31.510^{\star} 103 \mathrm{~N}$ \\
\hline Accurate Dynamic Factor (Fd) & $F+\frac{21 V(b * C+F t)}{(21 V+\sqrt{b * C+F t)}}$ & $21.863^{\star} 103 \mathrm{~N}$ & $21.56^{*} 103 \mathrm{~N}$ \\
\hline Design Torque [Mt] & $M t * K * K d$ & $206.90 \mathrm{~N}-\mathrm{m}$ & $213.10 \mathrm{~N}-\mathrm{m}$ \\
\hline Contact Stress $\left[\sigma_{c}\right]$ & $C_{R} * H R C * k_{C l}$ & $852.64 \mathrm{~N} / \mathrm{mm}^{2}$ & $1142.5 \mathrm{~N} / \mathrm{mm}^{2}$ \\
\hline Calculation of Centre Distance & $a \geq(1+1)^{2} \sqrt{\left(\frac{0.74}{\sigma_{c}}\right)} Z * \frac{E_{e q}\left[M_{t}\right]}{1 \psi}$ & $155 \mathrm{~mm}$ & $141.08 \mathrm{~mm}$ \\
\hline Face Width $b$ & $\psi a$ & $58.56 \mathrm{~mm}$ & $44 \mathrm{~mm}$ \\
\hline $\begin{array}{l}\text { Revision of design torque of gear } \\
\text { [Mt] }\end{array}$ & Mt ${ }^{*} k^{*} k d$ & $297.05 \mathrm{~N}-\mathrm{m}$ & $307.29 \mathrm{~N}-\mathrm{m}$ \\
\hline Contact stress ó ${ }_{c}$ & $\sigma_{c}=0.74(i+1) / 2 \sqrt{\left(\frac{1+1}{i b}\right)} * E_{e q}\left[M_{t}\right]$ & $494 \mathrm{~N} / \mathrm{mm}^{2}$ & $483 \mathrm{~N} / \mathrm{mm}^{2}$ \\
\hline
\end{tabular}




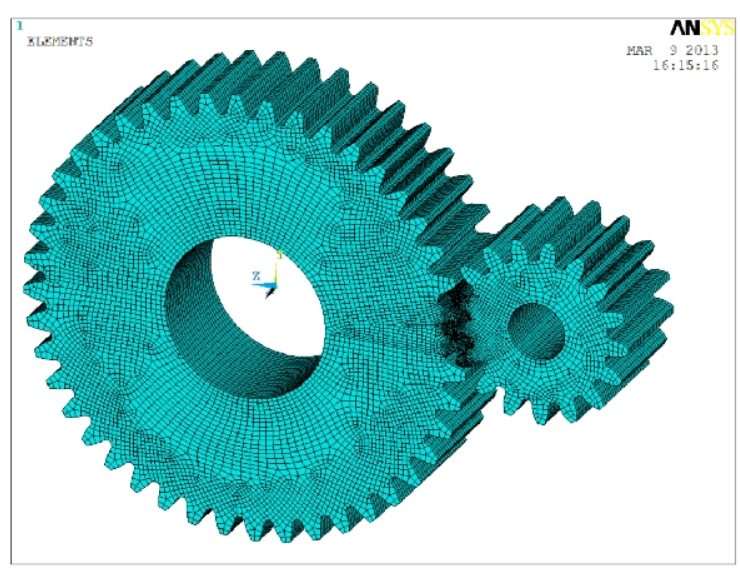

Fig. 4. Meshing of Spur gear for Steel C45

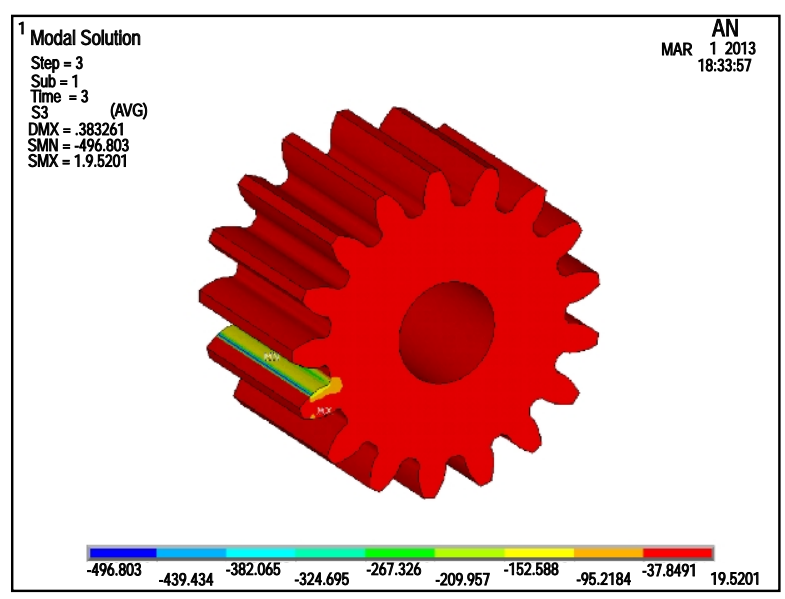

Fig. 5. Contact stress model of Spur gear for Steel C45

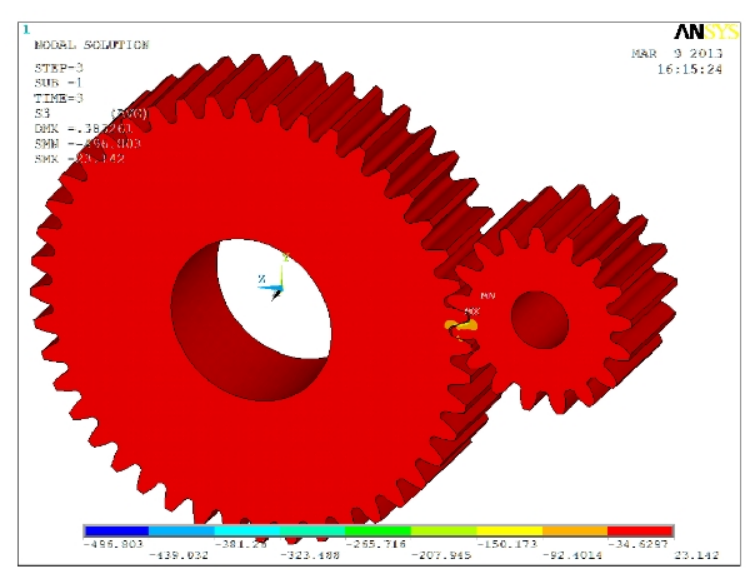

Fig. 6. Contact stress model of Spur gear for Steel C45

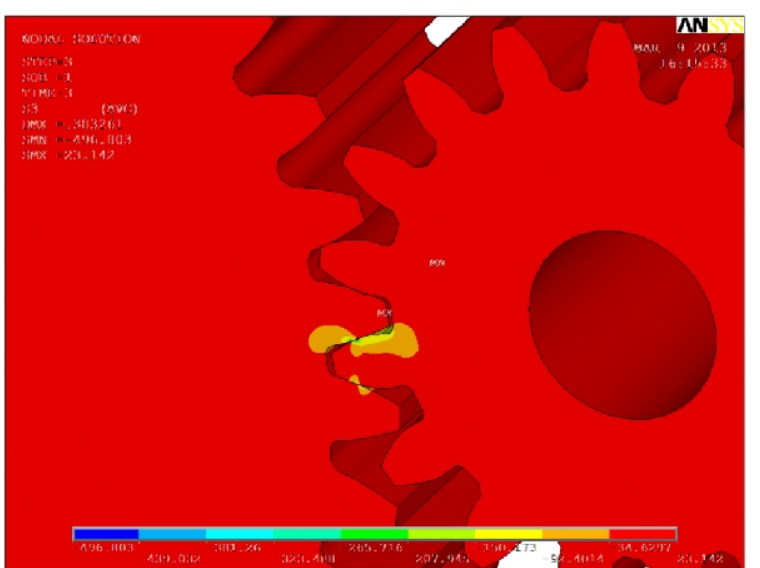

Fig. 7. Contact stress model of Spur gear for Steel C45

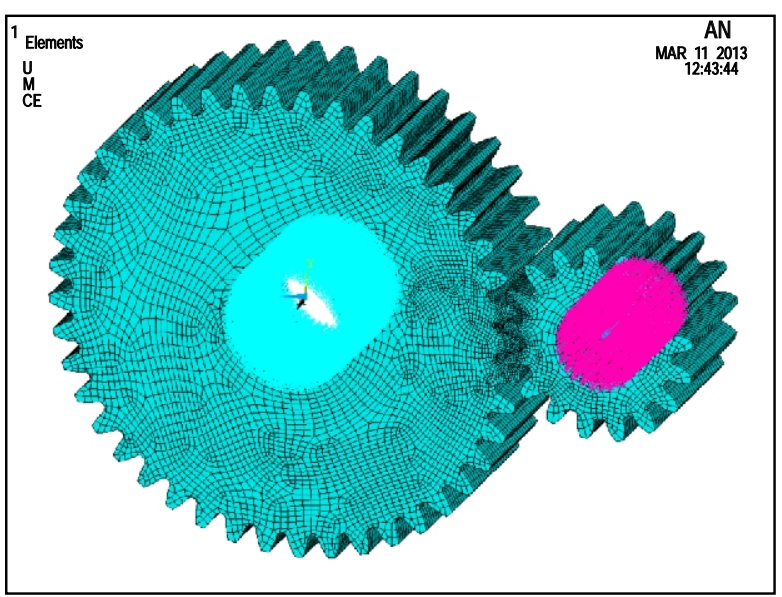

Fig. 8. Meshing of Spur gear for Steel $40 \mathrm{Ni}$ 2Cr1Mo28

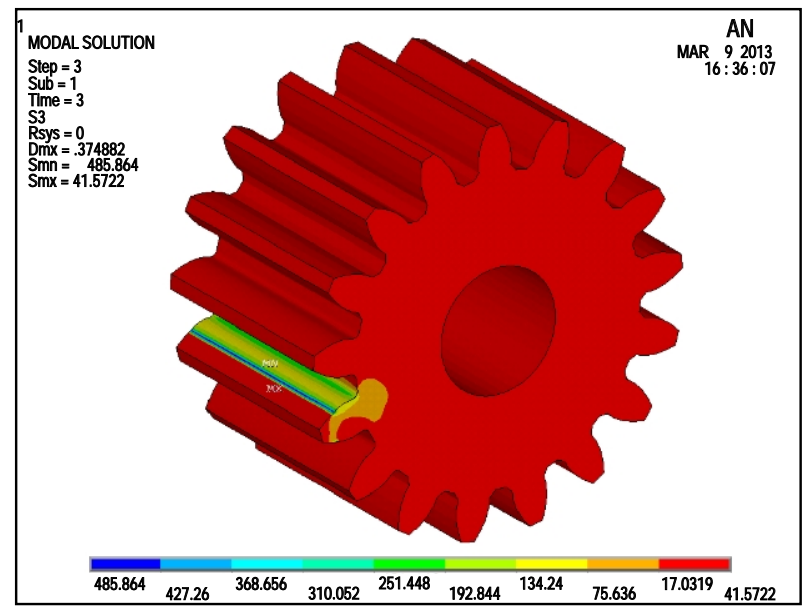

Fig. 9. Contact stress model of Spur gear for Steel 40Ni 2Cr1Mo28 


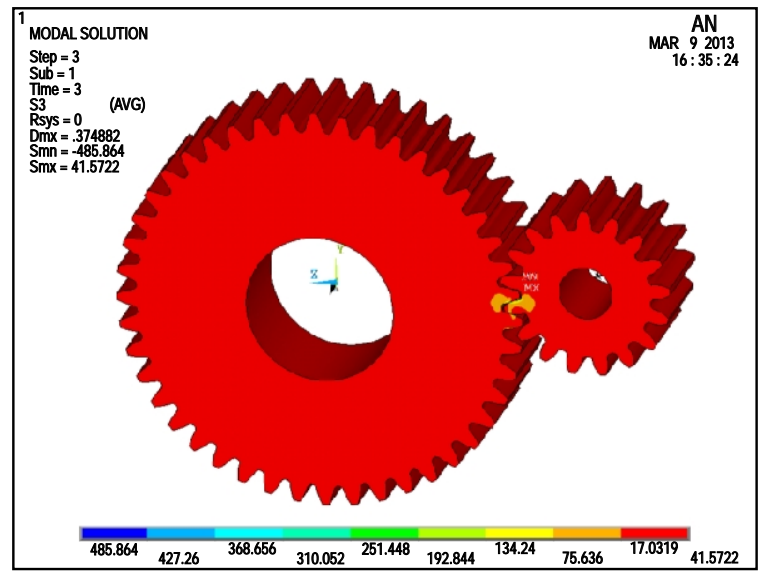

Fig. 10. Contact stress model of Spur gear for Steel 40Ni 2Cr1Mo28

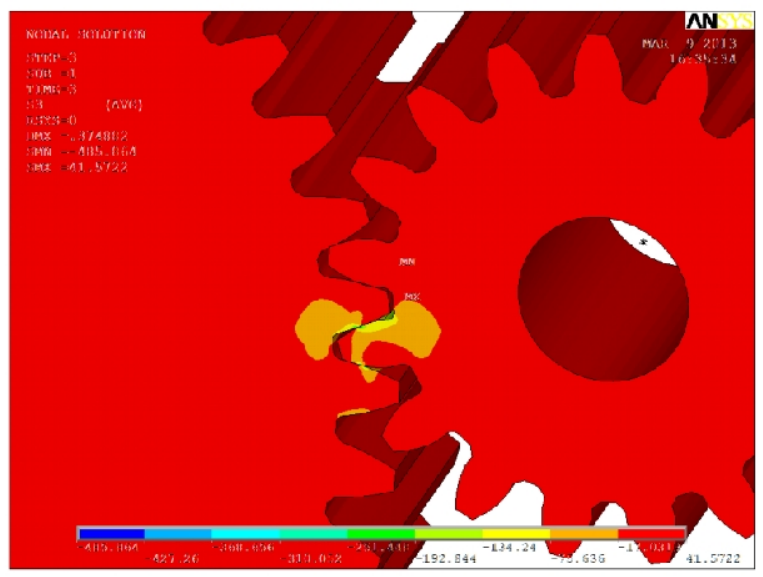

Fig. 11. Contact stress model of Spur gear for Steel 40Ni 2Cr1Mo28

Table 4.Comparison between Theoretical Value and FEA for spur Gear design

\begin{tabular}{|c|c|c|c|c|}
\hline Description & \multicolumn{2}{|c|}{ Theoretical } & \multicolumn{2}{c|}{ FEA } \\
\hline Material & Steel & Steel & Steel & Steel \\
& C45 & $\begin{array}{c}40 \mathrm{Ni} \\
\text { 2Cr1M028 }\end{array}$ & C45 & $\begin{array}{c}40 \mathrm{Ni} \\
2 \mathrm{Cr} 1 \mathrm{Mo28}\end{array}$ \\
& & & & \\
\hline Contact & 494 & 483 & 496.80 & 485.86 \\
Stress & $\mathrm{N} / \mathrm{mm}^{2}$ & $\mathrm{~N} / \mathrm{mm}^{2}$ & $\mathrm{~N} / \mathrm{mm}^{2}$ & $\mathrm{~N} / \mathrm{mm}^{2}$ \\
\hline
\end{tabular}

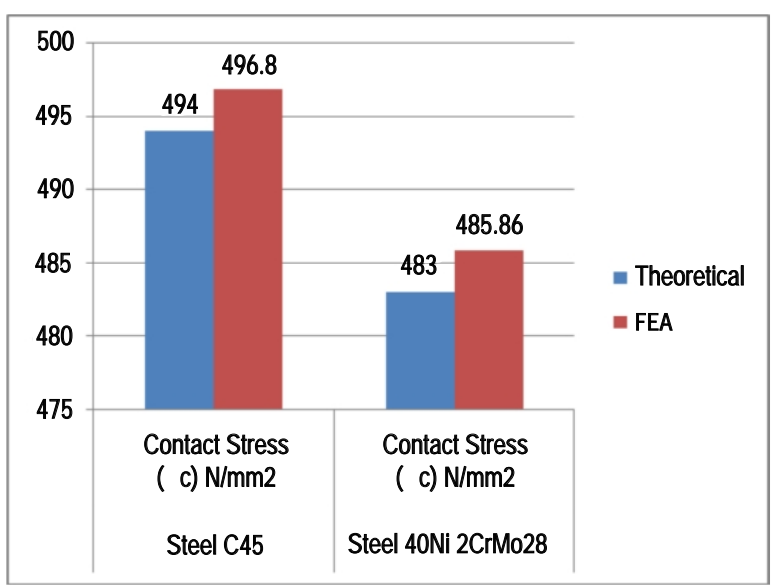

Fig. 12. Comparison between Theoretical value and FEA of spur gear for Steel C45 and Steel 40Ni $2 \mathrm{Cr} 1 \mathrm{Mo} 28$

Table 3 shown the results obtained and they are explained through Fig. 4 to Fig. 11. Table 4. shows the comparison and it is explained in Fig. 12,

\section{CONCLUSION}

In the present study, effective methods to estimate the contact stress by the three-dimensional finite element method are proposed. To determine the accuracy of the present method for the contact stress three dimensional models were built in this paper. So those FEA models are good enough for stress analysis. The comparison results for the geometry of the spur gear of a two different module using three dimensional finite element analysis and theoretical calculation were obtained. The result reveals that the stress values computed theoretically and by finite element analysis were safe and within the allowable limit. The contact stress for steel C45 and Steel 40Ni 2Cr1Mo28 are within the allowable limit for both theoretical and finite element model methods. Both results agree very well. This indicates that the Finite element analysis model is accurate

\section{NOTATIONS}

$\mathrm{m}_{\mathrm{n}}: \quad$ Normal Module in $\mathrm{mm}$

$\mathrm{N}_{1}, \mathrm{~N}_{2}$ : Speed of Gear,Pinion in rpm

$\mathrm{P}$ : $\quad$ Power transmitted in $\mathrm{kW}$

i: $\quad$ Gear (or) transmission ratio Gear in $\mathrm{mm}$.

$\mathrm{b}$ : $\quad$ Thickness of gear and pinion in $\mathrm{mm}$ 
a: $\quad$ Centre distance between shafts in $\mathrm{mm}$

$z_{1}, z_{2}$ : Number of teeth in pinion

$d_{1}, d_{2}$ : Pitch circle diameter of pinion,

$\alpha: \quad$ Normal Pressure angle (helical gear)

$\rho$ : $\quad$ Density of the material in $\mathrm{kg} / \mathrm{mm}^{3}$

E: $\quad$ Young's modulus in $\mathrm{N} / \mathrm{mm}^{2}$

$\mathrm{V}_{1}$ : $\quad$ Pitch Line Velocity

$\left[\mathrm{M}_{\mathrm{t}}\right]$ : Design twisting moment in $\mathrm{N}-\mathrm{mm}$

y: $\quad$ Form factor

fo: Height factor

$\mathrm{k}$ : Load concentration factor

$\mathrm{k}_{\mathrm{d}}$ : $\quad$ Dynamic load factor

$\mathrm{k}_{\mathrm{b}}$ : $\quad$ Life factor for bending

$k_{\sigma}$ : Stress concentration factor for the fillet

$\mathrm{n}$ : Factor of safety

$\sigma_{c} \quad$ Induced contact stress in $\mathrm{N} / \mathrm{mm}^{2}$

$\left[\sigma_{c}\right]: \quad$ Allowable contact stress in $\mathrm{N} / \mathrm{mm}^{2}$

\section{REFERENCES}

[1] Hamrock, B.J., Jacobson, S.R., "Fundamentals of Machine Elements".

[2] Bharat Gupta, Abhishek Choubey, Gautam V. Varde., V 2012., "contact stress analysis of spur gear"
International Journal of Engineering Research \& Technology, Vol.1 Issue 4.

[3] Sushil Kumar Tiwari, Upendra Kumar Joshi, 2012, "Stress Analysis of Mating Involute Spur Gear Teeth" International Journal of Engineering Research \& Technology Vol. 1 Issue 9.

[4] Ali Raad Hassan 2009 "Contact Stress Analysis of Spur Gear Teeth Pair" World Academy of Science, Engineering and Technology Vol.34.

[5] Buckingham, E.,1949, "Analytical Mechanics of Gears", McGraw-Hill, New York.

[6] Savage, M., Coy, J.J., 1980, "Optimal Tooth Number for Compact Standard Spur Gear Sets", by Journal of Mechanical Design, vol.104 749-777.

[7] Cockerham, G.,1967, "Computer-Aided Design of Spur or0 Helical Gear Train", Computer-Aided Design, Vol.8 No. 2, pp. 84-88.

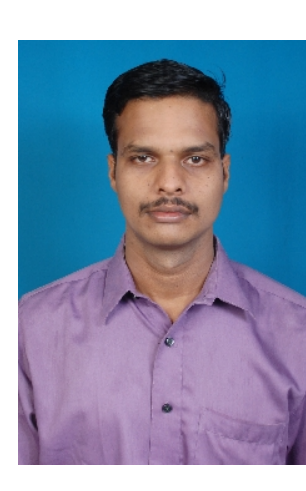

Prabhakaran.S is working as a Associate Professor in the Department of Mechanical Engineering at Anand Institute of Higher Technology, Chennai. He has completed has Bachelor degree in Mechanical Engineering in the year 2001 and Master degree in CAD in the year Dec 2002. He has more than 10 years of experience in the teaching field and he is pursuing Ph.D degree (Part Time) in Sathyabama University. 